\title{
SYSTEMIC LUPUS ERYTHEMATOSUS IN PREGNANCY WITH HAEMOLYTIC ANAEMIA, LEUCOPENIA AND THROMBOCYTOPENIA IN THE MOTHER AND HER NEWBORN INFANT
}

\author{
BY \\ MARTIN SEIP \\ From the Children's Department, University Hospital, Oslo, Norway
}

(RECEIVED FOR PUBLICATION SEPTEMBER 17, 1959)

Pregnancy in a patient with systemic lupus erythematosus is not extremely rare. However, very few reports dealing with the simultaneous occurrence of the disease or some of its manifestations in the mother and her newborn infant have been published. In the University Hospital, Oslo, we have observed a young woman with subacute systemic lupus erythematosus, whose newborn son for some time after birth presented haematological changes similar to those of his mother, probably due to passage of antibodies across the placental barrier.

\section{Case Report}

A housewife, 29 years of age, developed generalized lymphadenopathy, leucopenia and elevation of the erythrocyte sedimentation rate in February, 1958, during her fourth pregnancy. She had had an abortion in 1952 and a miscarriage in 1957. In 1953 she gave birth to a child who is living and well. In January, 1958, she was inoculated with BCG vaccine because her husband had contracted a tuberculous infection. She remained in fairly good condition until the beginning of July, 1958, when proteinuria, haematuria and anaemia developed. She was then admitted to the local hospital, where normal, spontaneous delivery took place on July $14,1958$.

Following delivery the patient developed a high, fluctuating fever which was not influenced by treatment with antibiotics in large doses. Her general health was poor and she suffered from pains in the chest and shoulders. Marked leucopenia with moderate eosinophilia was present. The haemoglobin dropped to about 7 g. $\%$, and there were obvious signs of increased haemolysis: reticulocytosis and a positive Coombs test. Two blood transfusions had only transient effect and she was transferred to Medical Department A, University Hospital, Oslo, on October 4, 1958, while her 12-week-old infant was admitted to our department.

On admission she was in poor condition with high fever, emaciation and pallor. Her haemoglobin level was 7 g. \%, but there were no longer signs of increased haemolysis. The Coombs test was only weakly positive. A weak red cell antibody, probably of the 'cold' type, could be demonstrated in her serum. She still had a persistent leucopenia with a minimum white cell count of 1,500 per c.mm. There were 171,000 blood platelets per c.mm. Erythrocyte sedimentation rate remained high, up to $133 \mathrm{~mm}$., during her stay in the hospital. Her urine contained about $0 \cdot 1 \%$ protein. Electrophoretic determination of the serum proteins showed a marked decrease in albumin $(1.8 \mathrm{~g} . \%)$, and a considerable increase in gamma globulin (3.3 g. \%). Typical L.E. cells could be demonstrated and a diagnosis of subacute systemic lupus erythematosus was made. Under treatment with corticosteroids she made good progress, and was. discharged on November 19, 1958. She is now receiving $10 \mathrm{mg}$. prednisone daily as a maintenance dose and is able to do her housework.

Her newborn infant looked somewhat pale at birth but otherwise appeared normal. He seemed to thrive fairly well on cow's milk during his first weeks of life. Because of the mother's illness he remained in the local hospital. After a few weeks his paleness attracted the nurse's attention. However, haematological studies were not performed until he was two months of age, when his general health seemed to be deteriorating. His haemoglobin level was then found to be $3 \cdot 3 \mathrm{~g} . \%$; a few days later it was $2.5 \mathrm{~g}$. $\%$; erythrocytes $1.23 \mathrm{~m} . / \mathrm{c} . \mathrm{mm}$; reticulocytes, $22.8 \%$; leucocytes $1,800 /$ c.mm. Bone marrow smears showed marked erythroid hyperplasia. Within two weeks five transfusions of whole blood had to be given, $500 \mathrm{ml}$. in all, but there was only transient effect on the haemoglobin level. A Coombs test, performed after the first blood transfusions were given, was equivocal.

He was transferred to the University Hospital, Oslo, on October 4, 1958, when 12 weeks old. He was slightly jaundiced with serum bilirubin $2.4 \mathrm{mg}$. $\%$. His spleen was moderately enlarged. He had just received a blood transfusion, which had brought his haemoglobin up to $10 \cdot 3 \mathrm{~g} . \%$. The white cell count had risen to 5,900 , 
the differential count was normal, blood platelets 114,000 . L.E. cells could not be demonstrated. The Coombs test was now negative.

In three days his haemoglobin dropped to $5.8 \mathrm{~g}$., and his reticulocyte count rose to $13 \cdot 3 \%$. He was given a transfusion of $100 \mathrm{ml}$. whole blood, but three days later his haemoglobin level had once more fallen to $5.6 \mathrm{~g}$. On October 11, treatment with prednisone was begun. He was given $10 \mathrm{mg}$. per day in divided doses. Within two weeks the blood picture had become completely normal. The dosage of prednisone was gradually reduced and the medication was terminated on November 10,1958, since when he has remained quite well, with a normal blood picture.

Except for the haematological changes we could find no signs of systemic lupus erythematosus in this patient. An electrophoretic determination of his serum proteins revealed a gamma globulin level of $1.2 \mathrm{~g}$. $\%$, which is relatively high for an infant 3 months of age. Otherwise the serum proteins were normal. $\mathrm{He}$ was group 0 $\mathrm{Fy}(\mathrm{a}-) \mathrm{K}-\mathrm{S}-\mathrm{Le}(\mathrm{a}+) \mathrm{Rh}+\left(\mathrm{R}_{\mathbf{1}} \mathbf{r}\right)$, his mother $\mathrm{A}_{\mathbf{1}}$ $F y(a-) K-S+\operatorname{Le}(a-) R h+$. No antibodies against the infant's red blood cells could be demonstrated in the mother's serum, and no platelet antibodies could be detected in either the mother's or the infant's serum (Dr. J. Lundevall). Technical facilities for studying leucocyte antibodies or foetomaternal leucocyte incompatibility were not available.

\section{Discussion}

In short, the case history reported was as follows: a woman, 29 years of age, became ill with subacute systemic lupus erythematosus during her fourth pregnancy. At the time of delivery an exacerbation of the disease occurred with haemolytic anaemia, positive Coombs test, leucopenia and possible thrombocytopenia. Her newborn infant developed similar haematologic manifestations, which, however, disappeared at $3 \frac{1}{2}$ months of age following treatment with blood transfusions and prednisone.

Pregnancy may be a serious complication to systemic lupus erythematosus, especially in the acute cases, with high maternal and foetal mortality. Ellis and Bereston (1952) collected a series of 69 cases from the United States, 56 with acute and 13 with subacute systemic lupus erythematosus. Treatment with corticosteroids had not been introduced at the time these patients were seen. Among the 56 acute cases 14 deaths were recorded in connexion with the pregnancy, and in addition 11 patients became worse. In the offspring there were 10 deaths in utero and six in the neonatal period. Among the 13 women with the subacute form of the disease there were no deaths in connexion with pregnancy or delivery, and a few of them even showed some improvement. In six the pregnancy terminated with abortion, while the other seven gave birth to living, apparently healthy infants. In chronic discoid lupus erythematosus, pregnancy does not seem to involve special hazards for mother or child.

Our knowledge about the causes of foetal or neonatal death as a result of maternal systemic lupus erythematosus is scanty. Hogg (1957) has described the necropsy findings in an infant who died on the second day of life, and who seemed to have signs of congenital systemic lupus erythematosus with typical vascular lesions. This child also had subendocardial fibroelastosis. Based on this observation Hogg advanced the hypothesis that subendocardial fibroelastosis may in some cases be due to a collagen disease. Other cases of congenital forms of the disease have not been reported. But Bridge and Foley (1954), and later other authors (Berlyne, Short and Vickers, 1957; Mijer and Olsen, 1958), were able to demonstrate placental transmission of the L.E. factor to the newborn infant. The L.E. test in these cases remained positive in the infant's blood until about 7 weeks of age, and then became negative. It is not surprising that this factor, being a gamma globulin, can pass the placental barrier.

Haematological manifestations in a newborn infant as a result of maternal systemic lupus erythematosus have not been previously reported. However, this may be partly due to the fact that they have not always been adequately searched for. We do not know precisely when our patient developed his pancytopenia. He looked pale even at birth. His paleness gradually increased, but his blood picture was not studied until he was 2 months old. A severe haemolytic anaemia and a marked leucopenia were then discovered. Blood platelets were not counted at that time. On admission to our department, when he was almost 12 weeks old, increased haemolysis could still be demonstrated. The leucopenia, however, was no longer present. A moderate thrombocytopenia with 114,000 blood platelets per c.mm. was found.

The fact that the patient has remained healthy and kept a normal blood picture since the age of $3 \frac{1}{2}$ months strongly supports the concept that his haematologic changes were caused by antibodies transferred from the mother. One must suppose (1) that the pancytopenia of this young woman with systemic lupus erythematosus was due to circulating antibodies, and (2) that there was placental transmission to the infant of these antibodies affecting erythrocytes, leucocytes and thrombocytes.

A similar mechanism is known to operate in chronic idiopathic thrombocytopenic purpura. About $60 \%$ of infants born of mothers with this disease get a transient thrombocytopenia, lasting for 
about two to four months after birth (Epstein, Lozner, Cobbey and Davidson, 1950; Nelson, 1954) and caused by placental transmission of maternal platelet antibodies.

Passage of red cell antibodies across the placental barrier is of course seen in erythroblastosis foetalis. In this disease, too, the haemolytic process may last for about three months. The occurrence of transient haemolytic anaemia in an infant born of a mother with autoimmune haemolytic anaemia, as in our case, has hitherto not been unequivocally demonstrated (Dacie, 1954; Söderhjelm, 1959), but might perhaps have been present in the case reported by Söderhjelm.

Transient leucopenia (granulocytopenia) in the neonatal period has been described in two siblings (Slobody, Abramson and Loizeaux, 1950; Lehndorff, 1951 ; Luhby and Slobody, 1956), but must be rare. The two siblings reported by Slobody and coworkers showed a marked granulocytopenia on the third day of life, with complete restitution in three to four weeks. The mother's blood picture was normal; leucocyte antibodies could not be demonstrated. Still, these authors advance the theory that the granulocytopenia might have been elicited by foetomaternal leucocyte incompatibility through a mechanism similar to that of the anaemia in haemolytic disease of the newborn. Payne and Rolfs (1958) have shown that multiparous women have a higher incidence of leucocyte antibodies in their serum than do those who have not been pregnant, a finding which may be due to foetomaternal leucocyte incompatibility. However, they report that so far not a single case of consequent neonatal leucopenia has been found. Simultaneous occurrence of leucopenia in a mother and her newborn infant has been reported in two families by Stefanini, Mele and Skinner (1958). In these cases the mothers were suffering from chronic neutropenia. The infants' blood picture became normal in three to four weeks after birth. In one case leucocyte antibodies could be demonstrated in both the mother's and her newborn infant's serum.

It has been assumed (Dausset, 1956) that the leucopenia in systemic lupus erythematosus may be caused by the presence of the L.E. factor which, as mentioned above, may pass the placental barrier. However, in newborn infants with a positive L.E. test hitherto reported in the literature, leucopenia has not been demonstrated. One cannot be certain whether it has not been present, or whether it has been overlooked.

\section{Summary}

A woman of 29 , developed signs of subacute systemic lupus erythematosus during her fourth pregnancy. In connexion with delivery an exacerbation of the disease occurred with pronounced haemolytic anaemia, a positive Coombs test, leucopenia, and a mild thrombocytopenia. Her newborn infant also developed a severe haemolytic anaemia, leucopenia and thrombocytopenia, but with complete restitution at $3 \frac{1}{2}$ months of age following treatment with blood transfusions and prednisone.

Placental transmission of the L.E. factor has been observed by several authors. A single case interpreted as congenital systemic lupus erythematosus has also been reported. But pancytopenia in a newborn infant caused by systemic lupus erythematosus in the mother does not seem to have been described before. The infant's haematological manifestations may be due to the passage of maternal antibodies against the formed elements across the placental barrier.

Infants born of mothers suffering from this should have their blood picture checked during the first months of life, particularly if the mother shows prominent haematological changes.

\section{REFERENCES}

Berlyne, G. M., Short, I. A. and Vickers, C. F. H. (1957). Placental transmission of the L.E. factor. Lancet, 2, 15 .

Bridge, R. G. and Foley, F. E. (1954). Placental transmission of the lupus erythematosus factor. Amer. J. med. Sci. 227,1 .

Dacie, J. V. (1954). The Haemolytic Anaemias: Congenital and Acquired. Churchill, London.

Dausset, J. (1956). Immuno-Hématologie Biologique et Clinique. Flammarion, Paris.

Ellis, F. A. and Bereston, E. S. (1952). Lupus erythematosus associated with pregnancy and menopause. A.M.A. Arch. Derm. Syph., 65, 170.

Epstein, R. D., Lozner, E. L., Cobbey, T. S. and Davidson, C. S. (1950). Congenital thrombocytopenic purpura. Amer.J. Med., $9,44$.

Hogg, G. R. (1957). Congenital, acute lupus erythematosus associated with subendocardial fibroelastosis. Amer. J. clin. Path., $28,648$.

Lehndorf, H. (1951). Transitorische Granulocytopenie beim Neugeborenen. Helv. paediat. Acta, 6, 173.

Luhby, A. L. and Slobody, L. B. (1956). Transient neonatal agranulocytosis in two siblings. Transplacental immunization to a leucocyte factor? Amer. J. Dis. Child., 92, 496.

Mijer, F. and Olsen, R. N. (1958). Transplacental passage of the L.E. factor. J. Pediat., 52, 690.

Nelson, W. E. (1954). Textbook of Paediatrics, 6th ed. Saunders, Philadelphia and London.

Payne, R. and Rolfs, M. R. (1958). Fetomaternal leukocyte incompatibility. J. clin. Invest., 37, 1756.

Slobody, L. B., Abramson, H. and Loizeaux, L. S. (1950). Agranulocytosis of the newborn infant. J. Amer. med. Ass.. 142, 25.

Söderhjelm, L. (1959). Non-spherocytic haemolytic anaemia in mother and new-born infant. Acta paediat. (Uppsala), 48, Suppl. 117, p. 34

Stefanini, M., Mele, R. H. and Skinner, D. (1958). Transitory congenital neutropenia: A new syndrome. Report of two cases. Amer. J. Med., 25, 749 .

Talbott, J. H. and Moleres Ferrandis, R. (1956). Collagen Diseases. Grune and Stratton, New York and London. 